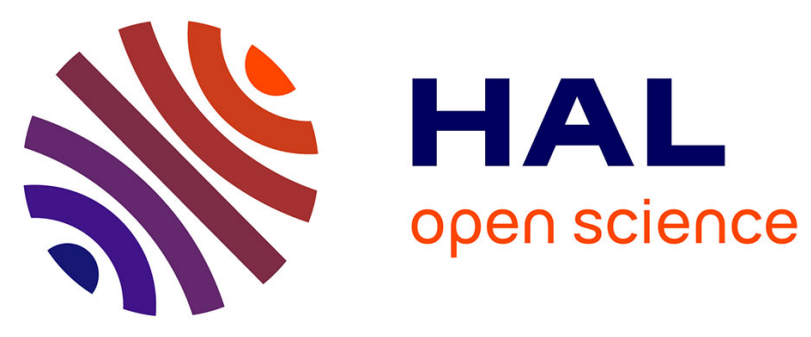

\title{
In vivo imaging of DNA lipid nanocapsules after systemic administration in a melanoma mouse model
}

Stephanie David, Nathalie Carmoy, Pauline Resnier, C.V. Denis, Laurent

Misery, Bruno Pitard, Jean-Pierre Benoit, Catherine Passirani-Malleret, Tristan Montier

\section{To cite this version:}

Stephanie David, Nathalie Carmoy, Pauline Resnier, C.V. Denis, Laurent Misery, et al.. In vivo imaging of DNA lipid nanocapsules after systemic administration in a melanoma mouse model. International Journal of Pharmaceutics, 2012, 423 (1), pp.108-15. 10.1016/j.ijpharm.2011.06.031 . hal03165465

\section{HAL Id: hal-03165465 \\ https://univ-angers.hal.science/hal-03165465}

Submitted on 10 Mar 2021

HAL is a multi-disciplinary open access archive for the deposit and dissemination of scientific research documents, whether they are published or not. The documents may come from teaching and research institutions in France or abroad, or from public or private research centers.
L'archive ouverte pluridisciplinaire HAL, est destinée au dépôt et à la diffusion de documents scientifiques de niveau recherche, publiés ou non, émanant des établissements d'enseignement et de recherche français ou étrangers, des laboratoires publics ou privés. 


\title{
In vivo imaging of DNA lipid nanocapsules after systemic administration in a melanoma mouse model
}

\author{
Stephanie David ${ }^{a, b, c}$, Nathalie Carmoy ${ }^{d}$, Pauline Resnier ${ }^{a, b}$, Caroline Denis $^{d}$, Laurent Misery ${ }^{\mathrm{e}}$, \\ Bruno Pitard ${ }^{\mathrm{c}}$, Jean-Pierre Benoit ${ }^{\mathrm{a}, \mathrm{b}}$, Catherine Passirani ${ }^{\mathrm{a}, \mathrm{b}, *}$, Tristan Montier ${ }^{\mathrm{d}, * *}$ \\ a LUNAM Université - Ingénierie de la Vectorisation Particulaire, F-49933 Angers, France \\ $\mathrm{b}$ INSERM U646, F-49933 Angers, France \\ c INSERM UMR915 - Université de Nantes, 8 quai Moncousu, F-44000 Nantes, France \\ d INSERM U613 - Université de Brest, 5 avenue du Maréchal Foch, F-29200 Brest, France \\ ${ }^{\mathrm{e}}$ Laboratoire de Neurobiologie de la Peau, Service de Dermatologie, CHU de Brest, F-29609 Brest, France
}

\section{A R T I C L E I N F O}

\section{Article history:}

Received 16 February 2011

Received in revised form 15 June 2011

Accepted 17 June 2011

Available online 24 June 2011

\section{Keywords:}

Skin cancer

DNA LNCS

Real-time imaging

pHSV-tk

Ganciclovir

Intravenous injection

\begin{abstract}
A B S T R A C T
The biodistribution of intravenously injected DNA lipid nanocapsules (DNA LNCs), encapsulating pHSV-tk, was analysed by in vivo imaging on an orthotopic melanoma mouse model and by a subsequent treatment with ganciclovir (GCV), using the gene-directed enzyme prodrug therapy (GDEPT) approach. Luminescent melanoma cells, implanted subcutaneously in the right flank of the mice, allowed us to follow tumour growth and tumour localisation with in vivo bioluminescence imaging (BLI). In parallel, DNA LNCs or PEG DNA LNCs (DNA LNCs recovered with $\mathrm{PEG}_{2000}$ ) encapsulating a fluorescent probe, DiD, allowed us to follow their biodistribution with in vivo biofluorescence imaging (BFI). The BF-images confirmed a prolonged circulation-time for PEG DNA LNCs as was previously observed on an ectotopic model of glioma; comparison with BL-images evidenced the colocalisation of PEG DNA LNCs and melanoma cells. After these promising results, treatment with PEG DNA LNCs and GCV on a few animals was performed and the treatment efficacy measured by BLI. The first results showed tumour growth reduction tendency and, once optimised, this therapy strategy could become a new option for melanoma treatment.
\end{abstract}

(C) 2011 Elsevier B.V. All rights reserved.

\section{Introduction}

In homeostatic conditions, melanocytes produce melanin and thus contribute to the pigmentation of skin and hair, protect the skin from damage by ultraviolet radiation, and prevent skin cancer (Lin and Fisher, 2007). But they are also precursors of melanoma, the most deadly form of skin cancer, following mutations of critical growth regulatory genes, the production of autocrine growth factors, and/or a loss of adhesion receptors (Gray-Schopfer et al., 2007). The primary site of melanoma is the skin, but other pigmented tissues, such as the eyes or the intestine, can also be at the origin of melanoma. The tumour-specific, 10-year survival for melanoma is $75-85 \%$ when diagnosed as primary tumours without any evidence of metastasis, but melanoma metastasis dramatically reduces this percentage to $20-70 \%$, this being dependent on the

\footnotetext{
* Corresponding author at: INSERM U646, IBS-CHU, 4 rue Larrey, 49933 Angers Cedex 9, France. Tel.: +33 244 688534; fax: +33 244688546.

** Corresponding author at: INSERM U613, Hopital Morvan - CHU Brest, 5 avenue du Maréchal Foch, 29200 Brest, France. Tel: +33 298 018080; fax: +33 298467910.

E-mail addresses: catherine.passirani@univ-angers.fr (C. Passirani),

Tristan.Montier@univ-brest.fr (T. Montier).
}

metastasis type (Garbe et al., 2010). If diagnosed early, local surgical resection can cure melanoma in $80 \%$ of cases, contrary to metastatic melanoma which is largely refractory to existing therapies (Tawbi and Nimmagadda, 2009).

For these reasons, new therapies need to be developed, and gene therapy, which is an emerging field in cancer treatment, represents a promising option. Gene therapy can be used with the aim of treating the tumour (destructive approach) or with the aim of reverting its malignant phenotype (corrective approach). One tumour-treatment possibility is the 'gene suicide' approach, also called gene-directed enzyme prodrug therapy (GDEPT). This approach is based on the delivery of a gene which codes for an enzyme, and is able to convert a nontoxic prodrug into a cytotoxic metabolite (Gutzmer and Guerry, 1998; Portsmouth et al., 2007). The first proof-of principle of GDEPT was made with the enzyme HSV-tk (Herpes simplex thymidine kinase) and the prodrug ganciclovir (GCV) (Moolten, 1986), which is still widely used in clinical and experimental applications in different tumour models (Portsmouth et al., 2007). The efficacy of this concept was for example shown in 2004 in a randomised controlled study on patients with operable primary or recurrent malignant glioma and allowed a significant increase in patient survival time (71 weeks in the treated group compared to 39 weeks in the control group) 
(Immonen et al., 2004). To transfer a gene effectively, different parameters, such as the administration route, the length of gene expression time, the animal model and/or the need of a delivery vehicle, have to be fixed. Local administration does not necessarily need a delivery vehicle and low doses are usually required; however, the targeted tissue has to be accessible to use this administration route. Systemic administration allows accessibility to the different tissues and has the advantage of rapid action and of allowing repeated administration but it needs a delivery vehicle in order to be effective. Moreover, in clinical applications, many diseases require intravenous (i.v.) or intraperitoneal (i.p.) injection treatment regimens. Delivery vehicles for systemic administration can be classified into two main groups: viral and non-viral delivery systems. Although viral vectors are very effective in terms of gene delivery and expression, the major drawbacks are their potential risk associated with replication-competent viruses, immunogenicity and high cost (Chowdhury, 2009; Collins et al., 2008; Jin and Ye, 2007). Non-viral vectors do not show these drawbacks; they present the advantages of being able to carry large inserts and to be easily formulated (Jin and Ye, 2007; Kreiss et al., 1999; Morille et al., 2008); they can also be adapted to passive or active tumour targeting (Huynh et al., 2010; Kang et al., 2010; Wagner et al., 2004).

In recent literature, nanocarriers (lipid or polymer) used in various treatment strategies, carrying different agents such as plasmids, siRNA, ODN or pharmacological inhibitors, and applied by several different administration routes (intravenous, intratumoural, topical, etc.), have been shown to increase melanoma cell delivery and treatment efficacy (de Campos et al., 2010; Stone et al., 2009; Weiss and Aplin, 2010; Zheng et al., 2009).

Lipid nanocapsules (LNCs) developed in our laboratory (Heurtault et al., 2002) have already been shown to be efficient for in vitro and in vivo transfection (Morille et al., 2009a, 2010). The formulation process of LNCs requires neither organic solvents nor high energy, and is based on the phase-inversion temperature (PIT) method. It consists of using non-ionic polyethoxylated surfactants to allow the phase inversion of an emulsion (Shinoda and Saito, 1968, 1969) and the application of a temperature-cycle treatment around the PIT to obtain small sizes with a low polydispersity index (PDI) (Anton et al., 2007). A sudden cooling and dilution of the micro-emulsion at the PIT leads to the obtention of LNCs, which consist of a lipid, liquid core of triglycerides, and a rigid shell of lecithin and short chains of poly(ethylene glycol) ( $\mathrm{PEG}_{660}$ ) (Heurtault et al., 2002). This formulation process allows fragile molecules such as nucleic acids to be encapsulated. To encapsulate hydrophilic DNA in the lipid core, DNA was complexed with cationic lipids prior to encapsulation (Vonarbourg et al., 2009). As already observed (Morille et al., 2009a; Vonarbourg et al., 2009), the encapsulation of these lipoplexes should provide an efficient loss of toxicity allowing higher doses to be injected in vivo. Furthermore, in order to enhance stealth properties of DNA LNCs, PEG was used (see the review of Huynh et al. (2010) describing the advantages and drawbacks of this polymer). The coating of the DNA-LNC surface with longer PEG chains $\left(\mathrm{PEG}_{2000}\right)$ improved nanocapsule in vivo circulation time on a mouse model of subcutaneously injected glioma cells (Morille et al., 2009a)

In this study, non-viral LNCs were used to deliver pHSV-tk in melanoma tumour cells after IV injection into mice. Considering the melanoma mice model, some luc+ human melanoma cells were engrafted on nude mice. Thus, the localisation and the growth of the tumours could be followed by luminescence. Once the tumours were established, the biodistribution and localisation of intravenously injected DNA LNCs in this orthotopic melanoma mouse model were traced via in vivo fluorescence imaging. Bioluminescence and fluorescence images were then compared in order to localise DNA LNCs versus PEG DNA LNCs, and a treatment with ganciclovir (GCV) was carried out in order to evaluate the efficiency of the gene suicide approach.

\section{Materials and methods}

\subsection{Preparation of nanocarriers}

\subsubsection{Liposomes and lipoplexes}

Solutions of DOTAP (1.2-DiOleoyl-3-TrimethylAmmoniumPropane) and DOPE (1.2-DiOleyl-sn-glycero-3PhosphoEthanolamine) in chloroform $(20 \mathrm{mg} / \mathrm{ml}$ ) (Avanti Polar Lipids, Inc., Alabaster, USA) were first dried by an evaporation process under vacuum and the formed lipid film was then hydrated with deionised water over night at $4{ }^{\circ} \mathrm{C}$. The next day, liposomes were sonicated for $20 \mathrm{~min}$ and lipoplexes were prepared. For their preparation, DOTAP/DOPE $(1 / 1, \mathrm{M} / \mathrm{M})$ liposomes were mixed with $660 \mu \mathrm{g}$ of HSV-tk encoding plasmid (pORF-TK- $\Delta \mathrm{CpG}$; InvivoGen; $4.35 \mathrm{~kb})$ at a charge ratio of $5(+/-)$ in $150 \mathrm{mM} \mathrm{NaCl}$.

\subsubsection{DNA-loaded lipid nanocapsules (DNA LNCS)}

LNCs were composed of lipophilic Labrafac ${ }^{\circledR}$ WL 1349 (Gatefossé S.A., Saint-Priest, France), a mixture of caprylic and capric acid triglycerides, oleic Plurol ${ }^{\circledR}$ (polyglyceryl-6 dioleate) which was kindly provided by Gatefossé S.A. (Saint-Priest, France), $\mathrm{NaCl}$ (Prolabo, Fontenay-sous-Bois, France), water (obtained from a Milli-Q-plus ${ }^{\circledR}$ system, Millipore, Paris, France) and Solutol ${ }^{\circledR}$ HS-15 (30\% of free polyethylene glycol 660 and $70 \%$ of polyethylene glycol 660 hydroxystearate (HS-PEG)) (BASF, Ludwigshafen, Germany). The formulation process is based on phase-inversions of a microemulsion described by Heurtault et al. (2002). Briefly, all the components, in a well defined ratio (3.9\% of oleic Plurol ${ }^{\circledR}(w / w)$, $5.9 \%$ of Solutol ${ }^{\circledR}(\mathrm{w} / \mathrm{w}), 9.9 \%$ of Labrafac ${ }^{\circledR}(\mathrm{w} / \mathrm{w}), 78.9 \%$ of water $(\mathrm{w} / \mathrm{w})$ and $1.4 \%$ of $\mathrm{NaCl})$, were mixed together under magnetic stirring and temperature cycles around the phase-inversiontemperature (PIT) were performed. In the last step, cold water was added (in a ratio 1:1.96) to dilute the emulsion and to form the LNCs. To formulate fluorescent DNA LNCs, lipoplexes were added instead of the formulation water (Vonarbourg et al., 2009), and a mixture of 1,1'-dioctadecyl-3,3,3',3'-tetramethylindodicarbocyanine perchlorate $($ DiD, em. $=644 \mathrm{~nm}$; exc. $=665 \mathrm{~nm})($ Invitrogen, Cergy-Pontoise, France) and Labrafac ${ }^{\circledR}$ replaced Labrafac ${ }^{\circledR}$ alone. To obtain the Labrafac ${ }^{\circledR}$-DiD mixture, a solution of DiD in acetone at $0.6 \%(\mathrm{w} / \mathrm{w})$ was prepared, incorporated in Labrafac ${ }^{\circledR}$ in a ratio of $1: 10(\mathrm{w} / \mathrm{w})$ and acetone was evaporated before use (Garcion et al., 2006).

\subsubsection{Preparation of coated nanocapsules by post-insertion}

Coated nanocapsules were prepared as previously described (Morille et al., 2009a). Briefly, fluorescent DNA LNCs were purified after their formulation, using PD10 Sephadex columns (Amersham Biosciences Europe, Orsay, France). To compensate for the dilution of our formulation and the desalting effect caused by this purification step, an ultrafiltration step was performed with MilliporeAmicon ${ }^{\circledR}$ Ultra-15 centrifugal filter devices (Millipore, St. Quentin-Yvelines, France) and the salt- and LNCconcentration were readjusted afterwards to obtain a physiologic concentration of $\mathrm{NaCl}(150 \mathrm{mM})$ and the initial concentration of LNCs $(152 \mathrm{~g} / \mathrm{l})$. These purified fluorescent DNA LNCs were then mixed with 1,2-DiStearoyl-sn-glycero-3-PhosphoEthanolamine$\mathrm{N}$-[methoxy(polyethyleneglycol)-2000] (DSPE-mPEG 2000) (Mean Molecular Weight $(\mathrm{MMW})=2805 \mathrm{~g} / \mathrm{mol}$ ) (Avanti Polar Lipids, Inc., Alabaster, USA) to obtain a final polymer concentration of $10 \mathrm{mM}$. The mixture was incubated for $4 \mathrm{~h}$ at $30^{\circ} \mathrm{C}$ and vortexed every $15 \mathrm{~min}$. 


\subsection{Characterisation of nanocarriers}

\subsubsection{Physicochemical characteristics of DNA LNCS}

Coated and non-coated fluorescent DNA LNCs were characterised using a Malvern Zetasizer ${ }^{\circledR}$ (Nano Series ZS, Malvern Instruments S.A., Worcestershire, UK). The formulation was diluted in a 1:100 ratio with deionised water and size and zeta potential measurements were performed with the same sample at $25^{\circ} \mathrm{C}$. All measurements were performed in triplicate and with similar conductivity values.

\subsubsection{Agarose gel electrophoresis}

The encapsulation and integrity of the DNA molecules after the process of nanocapsule formulation and post-insertion, were evaluated by agarose gel electrophoresis as described previously (Vonarbourg et al., 2009). Briefly, a treatment with Triton ${ }^{\circledR} \times 100$ (Sigma, Saint-Quentin Fallavier, France) was performed to destroy the LNCs. A volume of LNCs equivalent to $0.2 \mu \mathrm{g}$ of DNA before and after this treatment was mixed with gel-loading solution (Sigma, Saint-Quentin Fallavier, France) and deposited in each well of 1\% agarose gel containing ethidium bromide (Sigma, Saint-Quentin Fallavier, France). The migration time was about $30 \mathrm{~min}$, at $100 \mathrm{~V}$.

\subsection{In vivo fluorescence and bioluminescence imaging}

\subsubsection{Orthotopic mouse model of melanoma}

Six- to nine-week-old female, nude NMRI mice (Elevage Janvier, France) were housed and maintained at the University animal facility; they were processed in accordance with the Laboratory Animal Care Guidelines (NIH Publication 85-23, revised 1985) and with the agreement of the regional veterinary services (authorisation FR; 29-024).

Tumour bearing mice were prepared by injecting subcutaneously a suspension of $3 \times 10^{6}$ SK-Mel28 luct melanoma cells $\left(n^{\circ}\right.$ HTB-72-ATCC) in $100 \mu$ l of PBS $1 \mathrm{X}$ into the right flank of athymic nude NMRI mice (6-week-old females, 20-24g). The SK-Mel28 cell line had previously been transfected with a plasmid encoding the luciferase, and bearing the resistance gene to the neomycine (pTG11033; Transgene; $9.6 \mathrm{~kb}$ ). Under neomycine pressure, one clone was selected due to its high and stable expression of luciferase and its proliferative capacities. Thus, the stable luminescence of these cells allowed the localisation and growth of the tumours to be measured. Concerning immunohistological analyses, tumours were PS100+, Ag HMB45+ and Ag Melan-A+. All these criteria indicated the malignity and the melanomic nature of the tumours.

Three weeks after tumour implantation, $150 \mu \mathrm{l}$ of DNA LNCs or PEG DNA LNCs were administered by intravenous injection into the tail vein of the mice.

\subsubsection{In vivo bioluminescence imaging}

In order to follow the tumour cell growth of the luciferaseexpressing melanoma cells, non-invasive bioluminescence imaging (BLI) was performed after 19 days, immediately before injection of the nanoparticles, and $24 \mathrm{~h}$ and $48 \mathrm{~h}$ post-injection.

Mice to be imaged first received an intraperitoneal injection of highly purified synthetic D-luciferin $(4 \mathrm{mg}$ in $200 \mu \mathrm{L}$ of water; Interchim, France). Five minutes later, the animals were anaesthetised with a $4 \%$ air-isofluorane blend and maintained with a $2 \%$ air-isofluran mixture through a nose cone. Ten minutes after luciferin injection, luminescence images were acquired using an in vivo imaging system (NightOWL II; Berthold Technologies, Germany) and associated software (WinLight 32; Berthold, Germany) with a binning of $8 \times 8$ and exposure time of $4 \mathrm{~min}$. Luminescence images were then superimposed onto still images of each mouse. The signals were quantified within the regions of interest in units of photons per second.

\subsubsection{In vivo biofluorescence imaging}

Non-invasive fluorescent imaging (BFI) was performed $1 \mathrm{~h}, 3 \mathrm{~h}$, $5 \mathrm{~h}, 24 \mathrm{~h}$ and $48 \mathrm{~h}$ post-injection, using the BFI system of the NightOWL II (Berthold Technologies, Germany) equipped with cooled, slow-scan CCD camera and driven with the WinLight 32 software (Berthold Technology, Germany). Considering the fluorescent characteristics of the DiD fluorescent tag used to localise the nanoparticles, the $590 \mathrm{~nm}$ excitation and $655 \mathrm{~nm}$ emission filters were selected. In parallel, the light beam was kept constant for each fluorescent measurement, which was ideal with the ringlight, epi-illumination. As the ringlight was always set at the same height, the excitation energy on the sample would always be the same.

Each mouse was anaesthetised with a $4 \%$ air-isofluran blend. Once placed in the acquisition chamber, the anaesthesia of the mice was maintained with a $2 \%$ air-isofluran mixture throughout the experiment as described above. With the BFI system, the fluorescent acquisition time was $3 \mathrm{~s}$ and the fluorescent signal was then overlaid on a picture of each mouse.

\subsubsection{Treatment with ganciclovir (GCV)}

To evaluate the treatment efficacy, nude NMRI mice $(n=10)$ bearing subcutaneous melanomas were prepared as described above. Five weeks after tumour implantation, $150 \mu$ l PEG DNA LNCs were administrated by intravenous injection and the mice were treated twice a day with $150 \mu$ l ganciclovir [concentration $50 \mathrm{mg} / \mathrm{ml}$; InvivoGen] for 4 days. Bioluminescence imaging was performed once a day to follow and quantify tumour growth as described above. The control group $(n=5)$ was prepared in the same way for tumour establishment, but received no treatment.

\section{Results and discussion}

\subsection{Preparation and characterisation of DNA LNCS}

DNA LNCs encapsulating the fluorescent probe DiD and the plasmid HSV-tk were prepared, purified and then half of the formulation was covered with DSPE-PEG 2000 chains by post-insertion. Afterwards, agarose gel electrophoresis experiments were performed and demonstrated the encapsulation of the HSV-tk plasmid (Table 1). The first lane shows LNCs without treatment. As very low fluorescence is visible, we consider that the major part of the plasmid is encapsulated. The second lane shows LNCs with a treatment of Triton to destabilise the LNCs and hence liberate the encapsulated plasmid. Here, the fluorescence indicates that the plasmid is intact since only one distinct line is visible and corresponds to that of the plasmid alone (data not shown). The comparison of both electrophoresis gels shows no influence of the post-insertion process on the DNA encapsulation, since the plasmid is well encapsulated before and after post-insertion. These results also evidence that our original encapsulation method of lipoplexes in LNCs is valid for different kinds of plasmids. Indeed, this HSV-tk coding plasmid has been encapsulated for the first time in LNCs and shows similar characteristics to DNA LNCs encapsulating a luciferase-coding plasmid (Vonarbourg et al., 2009).

Both types of LNCs were then characterised by size and zeta potential measurements (Table 1 ). DNA LNCs are small particles with a size of $90 \mathrm{~nm}$, and a low polydispersity index of 0.18 . This result of PDI, inferior to 0.3 indicates a narrow size distribution of the system. The plasmid HSV-tk is complexed with cationic lipids prior to encapsulation which results in positively charged DNA LNCs with a zeta potential of $+31 \mathrm{mV}$. After post-insertion with DSPE-PEG 2000 , size measurements of PEG DNA LNCs showed a slight increase in size of about $6 \mathrm{~nm}$. An almost doubling of the 
Table 1

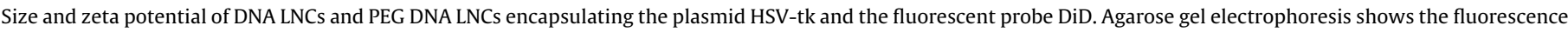
of DNA LNCs or PEG DNA LNCs before (first lane) and after (second lane) destruction with Triton.

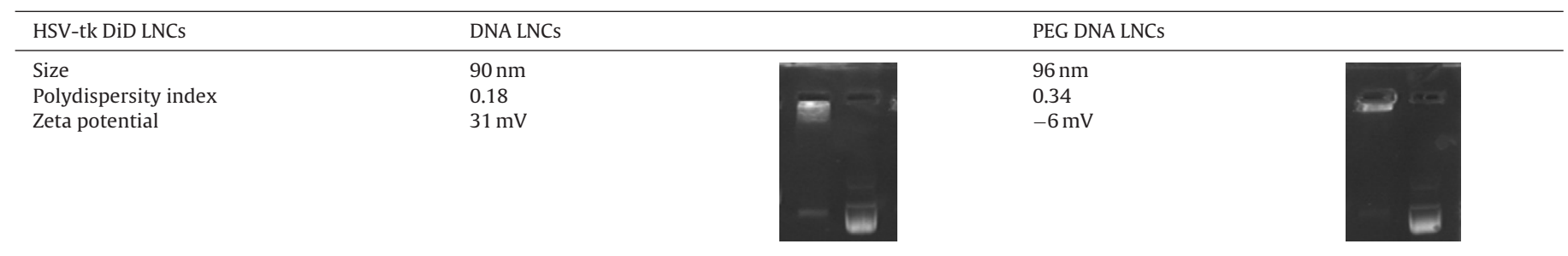

polydispersity index (0.34) was observed, proving the real insertion of some long chains of PEG at the surface of the nanocapsules. In contrast, the zeta potential diminished by $37 \mathrm{mV}$ from positive to near-neutral particles, as previously observed (Morille et al., 2009a). These results can be explained by the fact that DSPE$\mathrm{PEG}_{2000}$ chains carry negative, dipolar charges (Vonarbourg et al., 2005) and are thereby able to mask the positive surface charges due to the encapsulation of the positively charged lipoplexes. The positive surface charge of DNA-LNCs before post-insertion could help to interact with negatively charged cell membranes and lead to better internalisation and transfection effects in vitro as shown, for example, on Hela, H1299 or HEK293 33 cells (Morille et al., 2009b, 2010). However, positive surface charge can also interact with negatively charged proteins in the blood and dramatically reduce the circulation time in blood in comparison to PEG DNA LNCs (Morille et al., 2009a). In conclusion, the coating by longer PEG chains yielded small pegylated neutral particles and thus optimised the characteristics of the PEG DNA LNCs required for intravenous administration (Viola et al., 2010; Vonarbourg et al., 2006).

\subsection{The melanoma mouse model}

Luciferase-expressing melanoma cells were injected subcutaneously into the right flank of nude mice and, as the tumour growth was quite heterogeneous, the groups were drawn by chance. After tumour establishment, the tumours were dissected and histological analysis was carried out on fresh tumours in the anatomopathological service of the academical hospital ( $\mathrm{CHU}$ ) of Brest. There, the tumours were soaked in buffered formalin solution before their inclusion in paraffin. For standard examination, $3 \mu \mathrm{m}$ slices were prepared and coloured with hematoxyline-eosin-safran (HES). For immunohistochemical analysis, $5 \mu \mathrm{m}$ slices were prepared and deposited on glass slides. After rehydration of the probes, they were tagged with anti-PS100 antibodies (a marker of various cell types: melanocytes, nerve cells, sweat cells, etc.), anti-HMB45 antibodies, anti-Melan-A antibodies (marker of melanocytes) and Ki67 (cell proliferation marker). These analyses were carried out on several tumours.

In standard histology, a tumoural infiltration, constituted of cells presenting various atypical characteristics such as nuclei with voluminous nucleoli, and infiltrating the muscles in certain areas, was observed (see Fig. 1). In immunohistochemical analysis, positive labelling, to a greater or lesser extent, of the protein $S 100$, but also of the antigen HMB45 and Melan-A, was observed (see Fig. 1). All these criteria were compatible with the diagnosis of malignant tumours of melanocytic origin.

\subsection{Following the biodistribution of DNA LNCs by in vivo fluorescence imaging}

The formulated DNA LNCs and PEG DNA LNCs were injected three weeks after cell injection by intravenous injection in the tail vein of the mice. Biofluorescence imaging (BFI) was performed at different times after LNC administration ( 1 h, 3 h, 5 h, 24 h, and 48 h) to follow the tissue distribution of LNCs thanks to the encapsulated NIR fluorescent probe DiD (see Fig. 2). BFI is a fast, simple and low-cost method, and allows the number of sacrificed animals to be reduced, since it can be carried out on living animals at different times, but it is not an absolutely quantitative method as the absorption and diffusion of the visible light depends on the tissues (Goutayer et al., 2010). The NIR dye DiD has usually been used to follow the biodistribution of labelled molecules or nanocapsules, since the dye is not fluorescent in aqueous media, and the fluorescent signal cannot come from free DiD (Texier et al., 2009). Images were taken from lateral and decubitus dorsal views to obtain a general view of the biodistribution, and to better identify the organs and subjacent tissues which are more or less visible by BFI, depending on the position.

Images of mice which received DNA LNCs showed an intense fluorescence signal in the right flank, where the tumour cells had been grafted. A lower fluorescent signal was observed in the liver and uterus/ovaries, and persisted for only a few hours. Indeed, it was hardly visible $5 \mathrm{~h}$ after LNC injection, whereas an intense fluorescent signal persisted in the right flank and, was still visible $48 \mathrm{~h}$ after LNC administration. Images of mice that received PEG DNA LNCs revealed an intense fluorescent signal in the liver, the right flank, and the uterus/ovaries which was still visible $48 \mathrm{~h}$ after LNC injection. This is in concordance with the fact, that these tissues are highly vascular, have a high degree of microcirculation, and are sufficiently present at the body surface. However, contrary to the fluorescent signal of DNA LNCs, which presented a maximum at $1 \mathrm{~h}$ after LNC administration and diminished with time, the fluorescent signal of PEG DNA LNCs was relatively low at $1 \mathrm{~h}$ after LNC administration and then increased with a maximum at $3 \mathrm{~h}$ and $5 \mathrm{~h}$ after LNC administration. The fluorescent signal seems to be more important for PEG DNA LNCs than for DNA LNCs. In conclusion, the circulation time of PEG DNA LNCs is prolonged compared to that of DNA LNCs since intense fluorescence signals are obtained up to $48 \mathrm{~h}$ post-PEG DNA LNC-injection. Even if the tumour was different (glioma versus melanoma), a similar phenomenon has already been observed as a direct consequence of pegylation (Maeda et al., 2000; Morille et al., 2009a).

\subsection{Following the tumour cells by in vivo bioluminescence imaging and comparison of BLI and BFI images}

In parallel, tumour establishment and growth were followed by in vivo bioluminescence imaging (BLI) and BL- and BF-images were compared as shown in Fig. 3, to look more closely at the localisation of the LNCs versus the luciferase-expressing melanoma cells. BLI is based on the production of light from living luciferase cells due to a chemical reaction between the substrate luciferin, injected intraperitoneally before imaging, and ATP. This light is then captured externally by a cooled, charge-coupled device (CDD) camera (Hardy et al., 2001). The advantages of BLI are, as BFI, the sensitivity of the technology, the cost-effective instrumentation, the simple procedure and the significant reduction in 


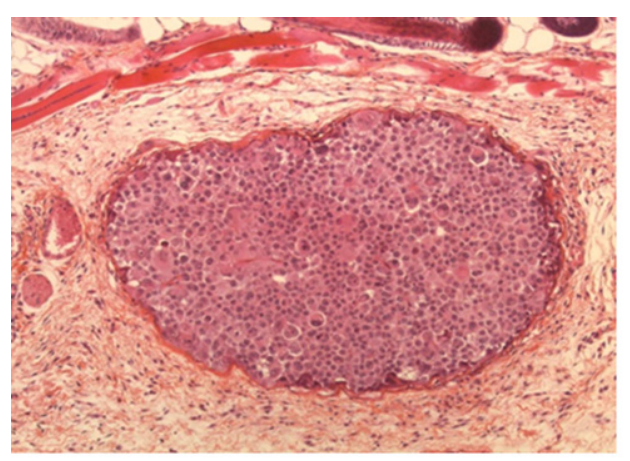

HES (x50)

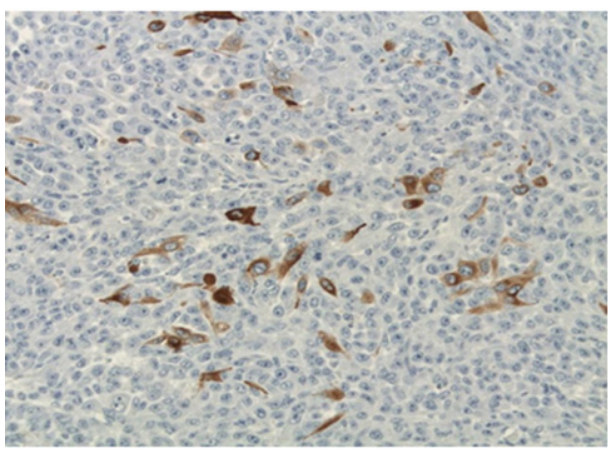

Melan-A (x200)

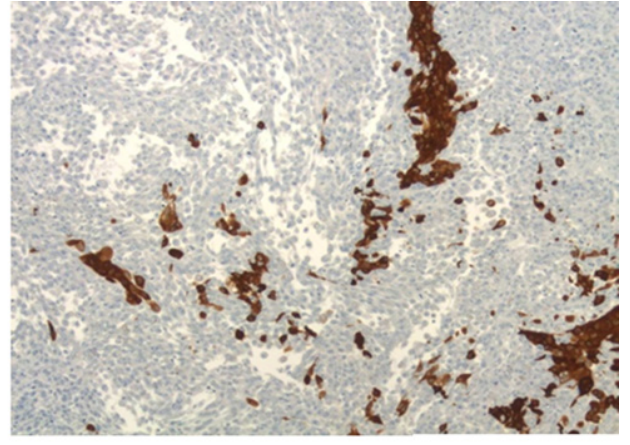

PS $100(x 100)$

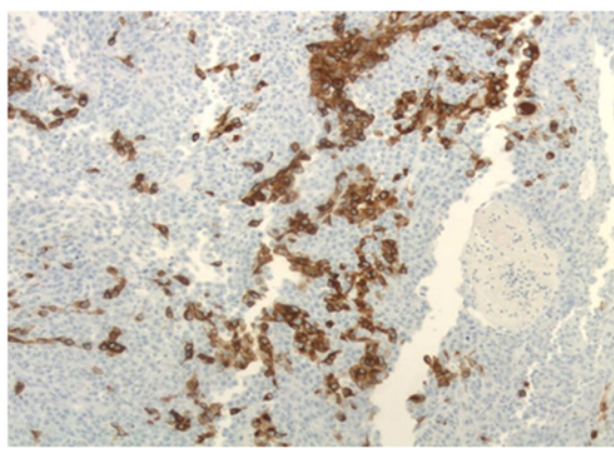

HMB45 (x200)

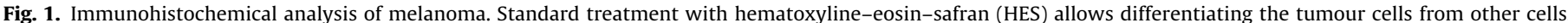
Treatment with PS100 antibody (PS100), Melan-A antibody or HMB45 antibody, evidences the malignity of the melanoma tumours.

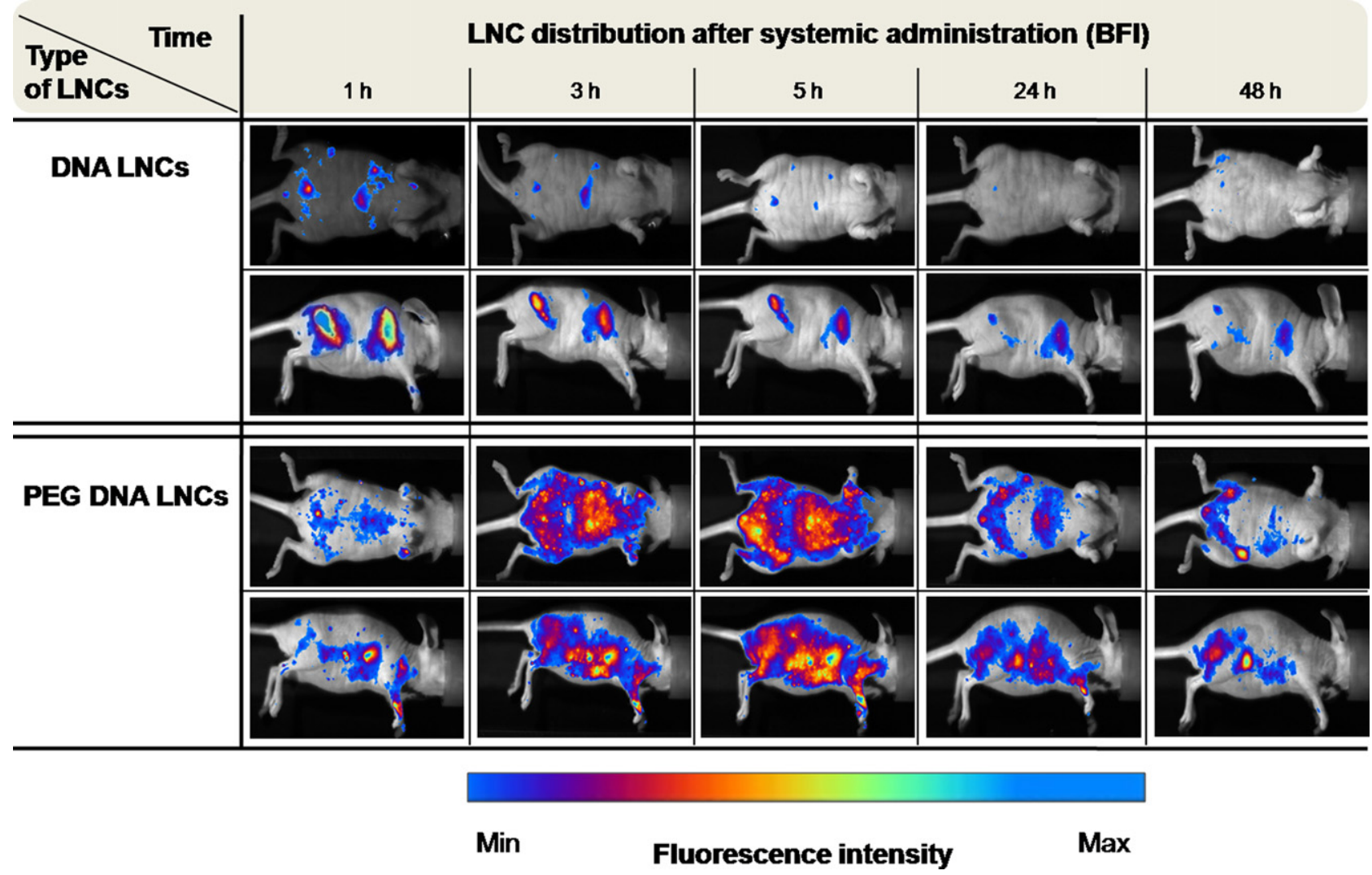

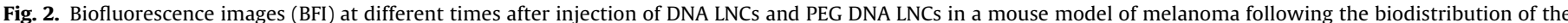

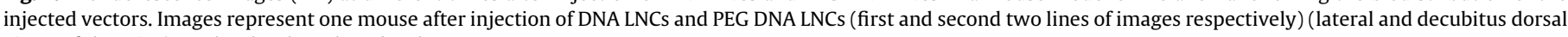
views of the mice) at $1 \mathrm{~h}, 3 \mathrm{~h}, 5 \mathrm{~h}, 24 \mathrm{~h}$ and $48 \mathrm{~h}$. 
the number of sacrificed animals (Roda et al., 2009). The location and growth of luciferase expressing melanoma cells can be monitored in real-time and, in contrast to BFI, quantified as photons per second. BL-images clearly show the location of luciferase-expressing melanoma cells in the right flank of the mice and quantification of the luciferase expression showed a mean luciferase expression of $3.3 \times 10^{6} \pm 4.0 \times 10^{6}$ photons/s before LNC injection for the group of mice that received DNA LNCs $(n=4)$ and $5.1 \times 10^{6} \pm 8.2 \times 10^{6}$ photons/s for the mice receiving the PEG DNA $\operatorname{LNCs}(n=4)$.

As seen in the previous section, PEG DNA LNCs had a prolonged circulation time compared to DNA LNCs, and provoked an intense fluorescent signal in the whole body at $5 \mathrm{~h}$, and a more specific localisation in the tumours at $24 \mathrm{~h}$. A comparison of the BF-images and BL-images showed a clear colocalisation of luciferase-expressing melanoma cells and fluorescent LNCs at $24 \mathrm{~h}$ after LNC administration. These observations confirm that DNA LNCs and PEG DNA LNCs attain the tumour site after intravenous administration via passive targeting, probably due to the enhanced permeability and retention (EPR) effect, which is known to be due to the combination of the leaky tumour vasculature and the low lymphatic drainage observed in the tumours in comparison to the healthy tissues (Maeda et al., 2000; Maeda, 2001).

\subsection{Intravenous administration of PEG DNA LNCS and subsequent treatment with ganciclovir}

After these promising results of colocalisation of PEG DNA LNCs and luciferase-expressing melanoma cells, the following step of the experiment was based on ganciclovir (GCV) treatment in order to evaluate if the tumour cells were transfected with the PEG DNA LNCs and if it could influence the tumour size. The gene-suicide approach, also called gene-directed enzyme prodrug therapy (GDEPT), is based on the introduction of a gene, in our case, the gene for the herpes simplex virus encoding thymidine kinase (HSV-tk) via the PEG DNA LNCs, which will sensitise the tumour cells to the subsequently delivered GCV. To do this, HSV-tk converts the inert prodrug GCV into the active triphosphorylated GCV (GCVTP) which will act as a chain terminator after incorporation into the DNA of dividing cells (Altaner, 2008; Gutzmer and Guerry, 1998; Portsmouth et al., 2007).

Nude NMRI mice, bearing subcutaneous melanoma cells, received one intravenous injection of PEG DNA LNCs and a GCV treatment twice a day for 4 days. This time period was chosen because the transfected tumour cells will inevitably die with the GCV treatment and therefore limit the time period of the therapeutic effect. Tumour establishment was followed by in vivo bioluminescence imaging as in the previous experiments and the PEG DNA LNCs followed via in vivo fluorescent imaging.

To see the treatment efficacy, in vivo bioluminescence imaging of luciferase-expressing melanoma cells was performed once a day during the treatment period, and 2 days after; the evolution of the luciferase-expression was quantified as photons per second (Fig. 4). On Day 1, the luciferase-expression diminished slightly for all the mice. Afterwards, until Day 3, the luciferase-expression increased with time. In the group of mice treated with LNCs and GCV, the increase seems to be lower than in the control group. At Day 4, a significant difference appears between the two groups with a

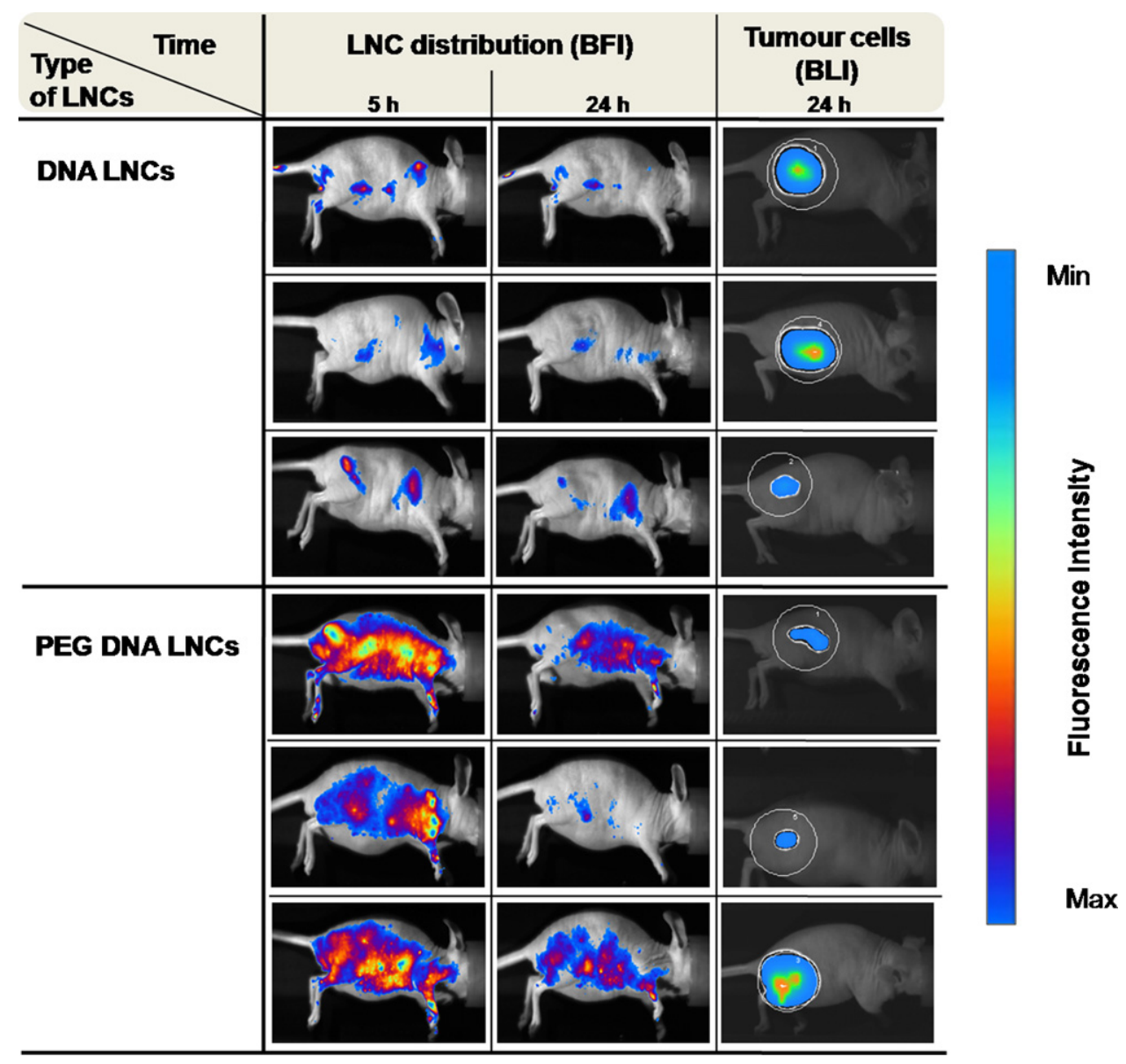

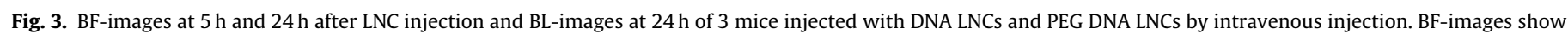
LNC distribution and BL-images melanoma cell localisation. 


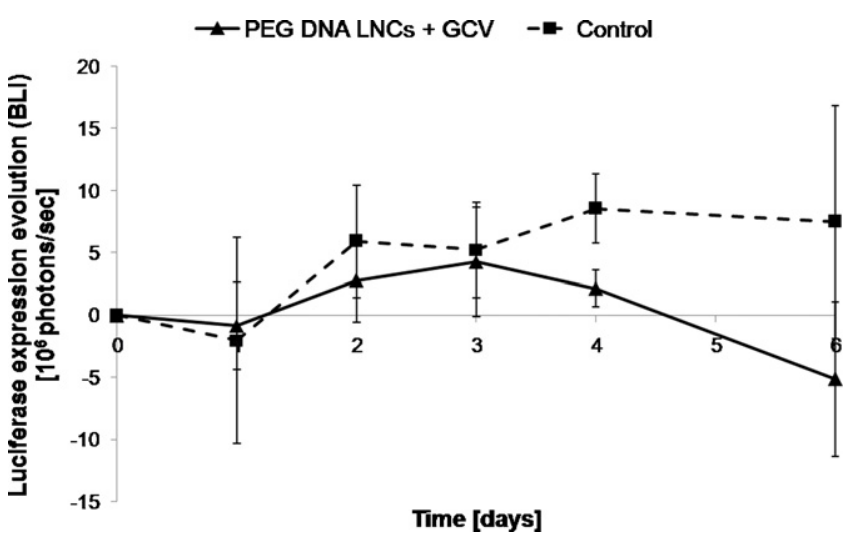

Fig. 4. Treatment efficacy of PEG DNA LNCs, encapsulating a plasmid coding for HSVtk, in combination with GCV of melanoma bearing mice in comparison to melanoma bearing mice without LNC administration and treatment (control, $n=5$ ). Mice were treated with one injection of PEG DNA LNCs at Day 0 and afterwards twice a day for 4 days with GCV $(n=10)$ by intraperitoneal injection.

decrease of luciferase-expression for the treated group. This difference seems to accentuate two days after the treatment period. However, considering the standard deviations certainly due to the heterogeneity of the tumour growth, another set of experiments including a large number of animals with similar tumour volumes needs to be carried out to confirm or not this therapeutic effect. Moreover, another group of control mice receiving only PEG DNA LNCs without a GCV treatment could be of interest, to evaluate the potential of a possible anti-tumour effect due to LNCs. A group receiving only GCV was realised but was not different from the control group (data not shown) confirming that GCV is only a prodrug and necessitates the presence of HSV-tk to be active.

In the literature, the gene-suicide therapy is often associated with a bystander effect. This bystander effect can either be direct on nearby cells or distant, by the induction of an immune response by natural killer cells or T-cells (Altaner, 2008). Although this bystander effect is a possibility, it is conditioned by the viability of the transfected cells. If these cells are killed too early, the bystander effect based on the transcytosis of GVC-monophosphate by passive diffusion or through gap junctions will be limited. Therefore, an important factor to take into account could be the time between the LNC administration and the GCV treatment. Here, the GCV treatment was given $8 \mathrm{~h}$ after the LNC injection, but a GCV administration one or two days after the LNC treatment did not show any treatment efficacy (data not shown). Another possibility to augment the treatment efficacy could be the repeated administration of PEG DNA LNCs after the gene-suicide effect.

Finally, as the passive tumour targeting by PEG LNCs was clearly demonstrated here, we plan now to test these formulations on a metastatic luc+ tumour mouse, increasing the number of experimental and control animals. In a metastatic melanoma mouse model, a systemic administration of the treatment would be highly required and, in such conditions, PEG LNCs could represent a new promising approach.

\section{Conclusion}

LNCs are promising non-viral gene delivery systems because they are well characterised, easy to formulate, adaptive to the targeted tissue and have previously proved to be efficient in term of transfection. Here, our first aim was to study the capacity of LNCs to target specifically a melanoma tumour engrafted on a mouse model, especially when PEG motifs were incorporated into the formulation, after IV injection in order to benefit of the perturbations of the stromal micro-vascularity and the EPR effect. As a second goal, we were interested to know if tumour cells were well transfected and could be led to death whereas the PEG DNA LNCs were colocalised into the tumours.

Using in vivo Bioluminescence and Biofluorescence imaging systems, the images showed on the one hand, prolonged circulation time of DNA LNCs coated with long PEG chains after i.v. injection compared to non-coated DNA LNCs, and on the other hand, for the first time, colocalisation of nanocapsules and luciferaseexpressing melanoma cells in mice for both types of DNA LNCs tested. These results confirmed the previous results obtained on an ectopic glioma mouse model but showed also their validity on an orthotopic melanoma mouse model.

Then, the treatment during 4 days with ganciclovir following the transfection of pHSV-tk carried out by PEG DNA LNCs showed, from Day 3, an interesting decrease of photons emitted by the luc+ tumours, reflecting probably the transfection of some cells and the action of GCV. These results are encouraging, even if further experiments have to be carried out to confirm this conclusion.

\section{Acknowledgements}

The authors would like to thank Marie Morille (Inserm U646, Angers, France) for her help and experience in the (PEG) DNA LNC formulation and the experimental setting as well as the platform SynNanoVect. This work is supported by grants from Région Pays de la Loire (CIMATH), Biogenouest, Région Bretagne, Ligue contre le cancer 29 and Canceropole Grand Ouest.

\section{References}

Altaner, C., 2008. Prodrug cancer gene therapy. Cancer Lett. 270, 191-201.

Anton, N., Gayet, P., Benoit, J.P., Saulnier, P., 2007. Nano-emulsions and nanocapsules by the PIT method: an investigation on the role of the temperature cycling on the emulsion phase inversion. Int. J. Pharm. 344, 44-52.

Chowdhury, E.H., 2009. Nuclear targeting of viral and non-viral DNA. Expert Opin. Drug Deliv. 6, 697-703.

Collins, S.A., Guinn, B.A., Harrison, P.T., Scallan, M.F., O’Sullivan, G.C., Tangney, M., 2008. Viral vectors in cancer immunotherapy: which vector for which strategy? Curr. Gene Ther. 8, 66-78.

de Campos, V.E., Teixeira, C.A., da Veiga, V.F., Ricci Jr., E., Holandino, C., 2010. LTyrosine-loaded nanoparticles increase the antitumoral activity of direct electric current in a metastatic melanoma cell model. Int. J. Nanomed. 5, 961-971.

Garbe, C., Peris, K., Hauschild, A., Saiag, P., Middleton, M., Spatz, A., Grob, J.J., Malvehy, J., Newton-Bishop, J., Stratigos, A., Pehamberger, H., Eggermont, A., 2010. Diagnosis and treatment of melanoma: European consensus-based interdisciplinary guideline. Eur. J. Cancer 46, 270-283.

Garcion, E., Lamprecht, A., Heurtault, B., Paillard, A., Aubert-Pouessel, A., Denizot, B., Menei, P., Benoit, J.P., 2006. A new generation of anticancer, drug-loaded, colloidal vectors reverses multidrug resistance in glioma and reduces tumor progression in rats. Mol. Cancer Ther. 5, 1710-1722.

Goutayer, M., Dufort, S., Josserand, V., Royere, A., Heinrich, E., Vinet, F., Bibette J., Coll, J.L., Texier, I., 2010. Tumor targeting of functionalized lipid nanoparticles: assessment by in vivo fluorescence imaging. Eur. J. Pharm. Biopharm. 75 , 137-147.

Gray-Schopfer, V., Wellbrock, C., Marais, R., 2007. Melanoma biology and new targeted therapy. Nature $445,851-857$.

Gutzmer, R., Guerry, D.t., 1998. Gene therapy for melanoma in humans. Hematol. Oncol. Clin. North Am. 12, 519-538.

Hardy, J., Edinger, M., Bachmann, M.H., Negrin, R.S., Fathman, C.G., Contag, C.H., 2001 Bioluminescence imaging of lymphocyte trafficking in vivo. Exp. Hematol. 29, 1353-1360.

Heurtault, B., Saulnier, P., Pech, B., Proust, J.E., Benoit, J.P., 2002. A novel phase inversion-based process for the preparation of lipid nanocarriers. Pharm. Res. $19,875-880$.

Huynh, N.T., Roger, E., Lautram, N., Benoit, J.P., Passirani, C., 2010. The rise and rise of stealth nanocarriers for cancer therapy: passive versus active targeting. Nanomedicine (Lond.) 5, 1415-1433.

Immonen, A., Vapalahti, M., Tyynela, K., Hurskainen, H., Sandmair, A., Vanninen, R., Langford, G., Murray, N., Yla-Herttuala, S., 2004. AdvHSV-tk gene therapy with intravenous ganciclovir improves survival in human malignant glioma: a randomised, controlled study. Mol. Ther. 10, 967-972.

Jin, S., Ye, K., 2007. Nanoparticle-mediated drug delivery and gene therapy. Biotechnol. Prog. 23, 32-41.

Kang, J.H., Toita, R., Katayama, Y., 2010. Bio and nanotechnological strategies for tumor-targeted gene therapy. Biotechnol. Adv. 28, 757-763.

Kreiss, P., Cameron, B., Rangara, R., Mailhe, P., Aguerre-Charriol, O., Airiau, M., Scherman, D., Crouzet, J., Pitard, B., 1999. Plasmid DNA size does not affect the 
physicochemical properties of lipoplexes but modulates gene transfer efficiency. Nucleic Acids Res. 27, 3792-3798.

Lin, J.Y., Fisher, D.E., 2007. Melanocyte biology and skin pigmentation. Nature 445, 843-850.

Maeda, H., Wu, J., Sawa, T., Matsumura, Y., Hori, K., 2000. Tumor vascular permeability and the EPR effect in macromolecular therapeutics: a review. J. Control. Release 65, 271-284.

Maeda, H., 2001. The enhanced permeability and retention (EPR) effect in tumor vasculature: the key role of tumor-selective macromolecular drug targeting. Adv. Enzyme Regul. 41, 189-207.

Moolten, F.L., 1986. Tumor chemosensitivity conferred by inserted herpes thymidine kinase genes: paradigm for a prospective cancer control strategy. Cancer Res. 46, 5276-5281.

Morille, M., Passirani, C., Vonarbourg, A., Clavreul, A., Benoit, J.P., 2008. Progress in developing cationic vectors for non-viral systemic gene therapy against cancer. Biomaterials 29, 3477-3496.

Morille, M., Montier, T., Legras, P., Carmoy, N., Brodin, P., Pitard, B., Benoit, J.P., Passirani, C., 2009a. Long-circulating DNA lipid nanocapsules as new vector for passive tumor targeting. Biomaterials 31, 321-329.

Morille, M., Passirani, C., Letrou-Bonneval, E., Benoit, J.P., Pitard, B., 2009b. Galactosylated DNA lipid nanocapsules for efficient hepatocyte targeting. Int. J. Pharm. 379, 293-300.

Morille, M., Passirani, C., Dufort, S., Bastiat, G., Pitard, B., Coll, J.L., Benoit, J.P., 2010 Tumor transfection after systemic injection of DNA lipid nanocapsules. Biomaterials.

Portsmouth, D., Hlavaty, J., Renner, M., 2007. Suicide genes for cancer therapy. Mol. Aspects Med. 28, 4-41.

Roda, A., Guardigli, M., Michelini, E., Mirasoli, M., 2009. Bioluminescence in analytical chemistry and in vivo imaging. TrAC Trends Anal. Chem. 28, 307-322.

Shinoda, K., Saito, H., 1968. The effect of temperature on the phase equilibria and the types of dispersions of the ternary system composed of water, cyclohexane, and nonionic surfactant. J. Colloid Interface Sci. 26, 70-74.
Shinoda, K., Saito, H., 1969. The stability of O/W type emulsions as functions of temperature and the HLB of emulsifiers: the emulsification by PIT-method. J. Colloid Interface Sci. 30, 258-263.

Stone, G.W., Barzee, S., Snarsky, V., Santucci, C., Tran, B., Langer, R., Zugates, G.T. Anderson, D.G., Kornbluth, R.S., 2009. Nanoparticle-delivered multimeric soluble CD40L DNA combined with Toll-Like Receptor agonists as a treatment for melanoma. PLoS One 4, e7334.

Tawbi, H., Nimmagadda, N., 2009. Targeted therapy in melanoma. Biologics 3, $475-484$.

Texier, I., Goutayer, M., Silva, A.D., Guyon, L., Djaker, N., Josserand, V., Neumann, E., Bibette, J., Vinet, F., 2009. Cyanine-loaded lipid nanoparticles for improved in vivo fluorescence imaging. J. Biomed. Opt. 14, 054005.

Viola, J.R., El-Andaloussi, S., Oprea, I.I., Smith, C.I., 2010. Non-viral nanovectors for gene delivery: factors that govern successful therapeutics. Expert Opin. Drug Deliv. 7, 721-735.

Vonarbourg, A., Saulnier, P., Passirani, C., Benoit, J.P., 2005. Electrokinetic properties of noncharged lipid nanocapsules: influence of the dipolar distribution at the interface. Electrophoresis 26, 2066-2075.

Vonarbourg, A., Passirani, C., Saulnier, P., Benoit, J.P., 2006. Parameters influencing the stealthiness of colloidal drug delivery systems. Biomaterials 27 , 4356-4373.

Vonarbourg, A., Passirani, C., Desigaux, L., Allard, E., Saulnier, P., Lambert, O., Benoit, J.P., Pitard, B., 2009. The encapsulation of DNA molecules within biomimetic lipid nanocapsules. Biomaterials 30, 3197-3204.

Wagner, E., Kircheis, R., Walker, G.F., 2004. Targeted nucleic acid delivery into tumors: new avenues for cancer therapy. Biomed. Pharmacother. 58, $152-161$.

Weiss, M.B., Aplin, A.E., 2010. Paying "particle" attention to novel melanoma treatment strategies. J. Invest. Dermatol. 130, 2699-2701.

Zheng, D., Li, X., Xu, H., Lu, X., Hu, Y., Fan, W., 2009. Study on docetaxel-loaded nanoparticles with high antitumor efficacy against malignant melanoma. Acta Biochim. Biophys. Sin. (Shanghai) 41, 578-587. 